\title{
Countermeasures and vaccination against terrorism using smallpox: pre-event and post-event smallpox vaccination and its contraindications
}

\author{
Hajime Sato
}

Received: 4 October 2010/Accepted: 16 November 2010/Published online: 21 December 2010

(C) The Japanese Society for Hygiene 2010

\begin{abstract}
Smallpox, when used as a biological weapon, presents a serious threat to civilian populations. Core components of the public health management of a terrorism attack using smallpox are: vaccination (ring vaccination and mass vaccination), adverse event monitoring, confirmed and suspected smallpox case management, contact management, identifying, tracing, monitoring contacts, and quarantine. Above all, pre-event and post-event vaccination is an indispensable part of the strategies. Since smallpox patients are most infectious from onset of the rash through the first 7-10 days of the rash, vaccination should be administered promptly within a limited time frame. However, vaccination can accompany complications, such as postvaccinial encephalitis, progressive vaccinia, eczema vaccinatum, and generalized vaccinia. Therefore, vaccination is not recommended for certain groups. Public health professionals, as well as physicians and government officials, should also be well equipped with all information necessary for appropriate and effective smallpox management in the face of such a bioterrorism attack.
\end{abstract}

Keywords Bioterrorism - Smallpox - Vaccination · Countermeasures $\cdot$ Public acceptance

\section{Introduction}

Terrorism can be defined as politically motivated violence or the threat of such violence, especially against civilians,

\section{H. Sato $(\square)$}

Department of Public Health, Graduate School of Medicine,

The University of Tokyo,

7-3-1 Hongo, Bunkyo-ku, Tokyo 113-0033, Japan

e-mail: hsato@m.u-tokyo.ac.jp with the intent to instill fear, harm or both. The main objective is to create psychological terror, which in turn can cause chaos and panic [1]. The first documented use of chemical weapons by terrorists occurred in Matsumoto, Japan, in 1994 and then a year later in the Tokyo metropolitan area [2]. These attacks made people worldwide realize that terrorist attacks could take place in a country that was believed to be one of the safest places in the world.

Biological weapons were first used thousands of years ago in Persia, Greece, and Rome. They were used in 1347 in the Crimea; in 1763 by the British during the French and Indian War; by Germany during WWI and WWII; and by Japanese troops and laboratories in the 1930s and during WWII. Great Britain and the United States developed anthrax spores during WWII, but they did not use them as weapons. After WWII, the US had a biological weapons program until the late 1960s and did not ratify the Biological Weapons Convention until 1975. The Soviet Union also had similar programs [3]. Later, an accidental release of anthrax spores from a Soviet biological weapons factory in 1979 caused an outbreak of inhalational anthrax. In 1984, the first bioterrorist attack occurred in Oregon perpetrated by members of a cult using Salmonella bacteria. Bioterrorism began to be perceived as a greater threat in the US following the 11 September 2001 attacks on the World Trade Center and the Pentagon, and especially following the dissemination of anthrax spores through the mail that same year.

In response to these incidents, the Centers for Disease Control and Prevention (CDC) developed three categories of biological agents, prioritized according to their likelihood of bioterrorist use and the severity of the disease that each could produce: category A (high priority), category B (second highest priority), and category $\mathrm{C}$ (third highest 
priority). Category A included anthrax, botulism, plague, smallpox, tularemia, and viral hemorrhagic fevers. In Japan, the law concerning the prevention of infectious diseases and the health services for the patients with such diseases (amended in November 2003) lists smallpox as category I, which also includes pathogens that can cause serious and irreversible damage to life and body, including Ebola hemorrhagic fever, Crimean-Congo hemorrhagic fever, smallpox, South American hemorrhagic fever, plague, Marburg virus disease, and Lassa fever. Possession of these pathogens is prohibited unless permitted by the Minister of Health, Labor, and Welfare. The law (amended in December 2006) also prohibits the possession, importation, and transfer of such pathogens.

Smallpox has long been feared as the most devastating of all infectious diseases [4]. The disease, once worldwide in scope, can cause disabilities and death in sufficient numbers to cripple a city or an entire region. With worldwide strenuous effort, however, smallpox was eradicated. The last smallpox case in Japan was reported in 1955, after which no naturally occurring case has been found (one person from India was found to suffer from smallpox in 1973 and 1974, respectively). Globally, smallpox was designated by the World Health Organization (WHO) as eradicated in 1977.

When used as a biological weapon, smallpox presents a serious threat to civilian populations because of its case fatality rate of $30 \%$ or higher among unvaccinated persons and the absence of any specific therapy. Historically, smallpox was first used as a biological weapon during the French and Indian Wars (1754-1767) by British forces in North America [5]. In the case of any bioterrorism attack using smallpox, a set of public health measures, especially the vaccination of high risk groups, and in some cases even mass vaccination, is critically important to decrease the death toll by containing the spread of the disease.

It is important then for public health professionals to have a good level of understanding of the disease and precise plans and guidelines in the event of a smallpox attack $[6,7]$. This article aims to provide key up-to-date information and analysis regarding the management of smallpox based upon an extensive literature review.

\section{Bioterrorism using smallpox}

Smallpox is a DNA virus, a member of the genus orthopoxvirus, which includes smallpox, monkeypox, vaccinia, and cowpox [8]. Of these, only smallpox is readily transmitted from person to person. It is a high priority, category A agent that poses a global, terrorism security risk [9].

After the implantation of the virus on the oropharyngeal or respiratory mucosa, an asymptomatic viremia develops on the 3rd or 4th day following implantation, and the second viremia starts on the 8th day, causing toxemia. Many patients then present with a high fever $\left(38.5-40.5^{\circ} \mathrm{C}\right)$ and the malaise of a prodromal illness (10-14 days after exposure). A maculopapular rash appears on the mucosa of the mouth and pharynx, face, and forearms, and spreads to the trunk and legs. Within 1-2 days, that rash becomes vesicular and later pustular. Neutralizing antibodies and hemagglutinin-inhibiting antibodies appear by the 6th day of the rash (21 days after infection), and crusts begin to form on the 8th or 9th day of the rash. The scabs separate with characteristic pitted scars. Secondary bacterial infection is not common, but death can result from toxemia during the 2nd week [10].

There are two principal forms of the disease, namely, variola major and variola minor [11]. The illness caused by variola minor is generally less severe, with fewer constitutional symptoms and a sparser rash. Most cases of smallpox are toxic, causing prostration. Severe, generalized headache, backache, chills, vomiting, and diarrhea have been reported in many cases. The mortality rate in smallpox has varied, but is reported to range generally from 30 to $50 \%$ among the unvaccinated. Death usually occurs between days 10-16 of the illness. In typical variola major epidemics, the case fatality rates have reached $30 \%$ or higher among the unvaccinated, whereas the epidemics of variola minor have had death rates of $1 \%$ or less [12]. With modern supportive therapy and antibiotic treatment of bacterial superinfection, mortality rates could be lower. However, this advantage might be counterbalanced if a strain of enhanced virulence were to be used in an attack.

Transmission of the smallpox virus occurs after onset of the rash. The patient is most infectious from onset of rash through the first 7-10 days of the rash [13, 14]. Virus titers in saliva are highest during this period. As scabs form, infectivity wanes rapidly. Smallpox spreads usually from person to person primarily in droplets expelled from the oropharynx, but also by contaminated clothing and bed linens [15]. An aerosol release of variola virus would disseminate widely, given the considerable stability of the orthopoxviruses in aerosol form and the likelihood that the infectious dose would be very small [16]. As many as 10-20 second-generation cases have sometimes been infected from a single case.

No antiviral substances have yet proven to be effective for the treatment of smallpox. It is suggested that cidofovir might be useful in preventing smallpox infection if administered within 1 or 2 days after exposure [17, 18]. Officially, variola virus is stocked only at the Institute of Virus Preparedness in Moscow, Russia, and at the CDC in Atlanta, Georgia. Concerns never disappear, however, about some suspect programs that can produce the smallpox virus in large quantities for use in bombs and 
intercontinental ballistic missiles or in smaller quantities for use as a means of bioterrorism [19].

If an outbreak of smallpox were to occur, multiple factors could contribute to a more rapid spread of smallpox than occurred before 1977, when this disease was eradicated: (1) virtually non-existent immunity to smallpox in the absence of the naturally occurring disease and the discontinuation of routine vaccination in the US in the early 1970s; (2) potentially delayed recognition of smallpox by health care personnel, who are unfamiliar with the disease; (3) increased mobility and crowding of populations; (4) potential use of more virulent, weaponized viruses with decreased incubation periods [20]. Therefore, its potential for devastation today is far greater than at any previous time, if it were to be used as a biological weapon.

\section{Management of smallpox terrorism}

After an insidious aerosol release of smallpox, the virus would rapidly spread in a modern highly susceptible population. A covert release of smallpox would probably go undetected until the first cases presented with the typical rash about 1-2 weeks after exposure. Isolation of these index cases, vaccination, and close follow-up of their known contacts would be recommended. During the incubation period of 12-14 days, there would be no risk of further environmental exposure from the original aerosol release, because the virus fully inactivates within 2 days (a ring-vaccination approach) [21].

Core components of the public health management of such a terrorism attack using smallpox would be: vaccination (ring vaccination and mass vaccination), adverse event monitoring, confirmed and suspected smallpox case management, contact management, identifying, tracing, and monitoring contacts, and quarantine. Here, smallpox vaccination strategies would encompass a set of vaccination programs [22] (Table 1).

It has been reported that the interval between vaccinations is significantly associated with vaccine "take" in both previously unvaccinated and vaccinated groups, and the median interval required for immunity after vaccination is estimated to be 6.4 and 4.3 days, respectively [23].

\section{Pre-event (pre-exposure) vaccination}

For a long time, inoculation (or variolation) was practiced to induce immunity against smallpox. It was already being widely conducted in many countries in the 16th century [24]. Edward Jenner demonstrated in 1796 that an infection caused by cowpox (vaccinia) protected against smallpox. This vaccine, which contained the vaccinia virus, was effective in protecting individuals from death if given within 3-4 days after exposure. The practice of cowpox inoculation (i.e., vaccination) rapidly spread worldwide [25].

From the 1950s through the 1970s, the smallpox vaccine was used in a concerted worldwide campaign to eradicate smallpox. That campaign featured detection of index cases and immunization of their potential contacts. A global campaign by the WHO started in 1967 and eventually succeeded in eradicating smallpox in 1977. The disease was declared eradicated worldwide as a natural infection in 1980 [26, 27]. Following recommendation by the World Health Assembly, many countries ceased routine vaccination [28]. In the US, for example, a mass vaccination program was discontinued in 1972. Routine vaccination for the US Armed Forces was also discontinued later in 1990 [29]. For many years, smallpox vaccination was approved by the US FDA for use only in persons in special task categories, such as laboratory workers.
Table 1 Smallpox vaccination programs

\begin{tabular}{ll}
\hline $\begin{array}{l}\text { Pre-exposure vaccination } \\
\text { 1. Selective pre-exposure vaccination: }\end{array}$ & $\begin{array}{l}\text { Vaccination of high-risk subpopulations before the } \\
\text { known release of the smallpox virus or the occurrence } \\
\text { of any smallpox cases } \\
\text { Vaccinating an entire population before the occurrence of any } \\
\text { smallpox cases or other known release of smallpox virus }\end{array}$ \\
Post-exposure vaccination & \\
1. Containment vaccination & $\begin{array}{l}\text { Vaccination of contacts of known smallpox cases, } \\
\text { accompanied by vaccination of their potential contacts } \\
\text { in anticipation of the original contact's becoming ill. } \\
\text { This might include vaccination of all persons in a } \\
\text { specific geographic area, also referred } \\
\text { to as a "ring vaccination" } \\
\text { Vaccinating an entire population after the occurrence } \\
\text { of a smallpox case or other documented release } \\
\text { of smallpox virus }\end{array}$ \\
\hline
\end{tabular}


In the US, the National Smallpox Vaccination Program was launched on 13 December 2002, and involved voluntary vaccination of 15,000 healthcare workers and first responders. Such a preemptive vaccination of hospital workers would reduce the number of smallpox cases and deaths. Vaccination of 500,000 active duty troops was also ordered [30]. This strategy was determined to be the best way to balance the unknown risk of a smallpox attack against the risks of vaccine-related adverse events associated with using the smallpox vaccine on the entire population [31, 32]. A total of approximately 40,000 persons were vaccinated by June 2003 [33].

In Japan, experimental inoculation with the powder from smallpox scabs was conducted by Shunsaku Ogata in the 1790s. Vaccinia vaccination was conducted nationwide after 1849. Vaccination against smallpox was mandated by law in 1909, and the incidence of the disease fast decreased. However, as the threat of smallpox became a past legacy, and the serious side effects of vaccination came to be highlighted as a social issue, the vaccination program gradually shrank by 1972 and finally was terminated completely in 1976, when the extinction of smallpox incidence was declared worldwide. As a result, many people under the age of 37 and most people younger than 33 have not been vaccinated against smallpox. In other words, those in this younger generation have no protection at all. It is unknown whether those who were vaccinated prior to 1972 remain immune.

Routine vaccination ceased more than 30 years ago. The immune status of those who were vaccinated more than 30 years ago is not clear. Neutralizing antibodies decline markedly during a 10-20 year period [34]. However, among a group who had been vaccinated at birth and again at ages 8 and 18 years, the antibody levels remained stable for a 30-year period [35]. It is also noted that, in endemic countries, estimates of vaccine efficacy after primary vaccination have been found to be $90 \%$ or higher among adults who were vaccinated only as children [36].

In the American pre-event vaccination program, many people (prospective vaccinees) were reportedly concerned about adverse reactions, likely reflecting their focus upon the potential risks of vaccination in a context of unclear benefit [37]. In general, the main deciding factor for voluntary vaccination is the risk of disease exposure and negative outcomes versus the benefits and risk of vaccination (vaccine effectiveness vis-a-vis individual vulnerability and concern about side effects) [38]. The leading reasons for non-vaccination were concern about side effects [39], the belief that the risk of outbreak (smallpox attack and exposure to it) was not high [40], and concern about contraindications among the participants or their household contacts [41]. This issue is discussed in another article in this journal [42].

\section{Post-event (after exposure) vaccination}

The effectiveness of the smallpox vaccine was established through post-exposure prophylaxis and outbreak containment. Post-exposure vaccination is highly effective in preventing smallpox when administered within 4 days of exposure [43]. First, the smallpox vaccine can be administered within 4 days after exposure to lessen the severity of, or even prevent, the illness [44]. Vaccination thus administered has been shown to provide some protection against acquiring the infection and significant protection against a fatal outcome [45]. Second, contacts, even if infected, are not contagious until onset of the rash. All individuals in whom smallpox is suspected should be isolated immediately, and all household and other face-toface contacts after the onset of fever, as well as their families, should be vaccinated and placed under surveillance [46]. An emergency vaccination program is also indicated for all health care workers and other disaster response personnel. Thus, during a smallpox emergency, vaccination of the population at risk is a critical containment strategy.

Ring vaccination, the targeted vaccination of specified persons, is a principal containment strategy to protect those at greatest risk for contracting smallpox. It forms a buffer of immune persons to prevent further spread of the disease, but mass vaccination might also be used in such a circumstance [22, 47]. Voluntary, large-scale, mass vaccination of part or all of the population might be helpful to supplement priority surveillance and containment and control strategies in areas with actual smallpox cases. It can also be used to reduce the population at risk for additional intentional releases of smallpox virus, if the probability of such occurrences is considered substantial, or to address heightened public or political concerns regarding access to voluntary vaccination. People vaccinated in the distant past may no longer be immune to smallpox infection [48]. Therefore, in the event of any intentional exposure, prompt vaccination of all contacts would be potentially lifesaving decisions.

In Japan, the Ministry of Health, Labor, and Welfare (MHLW) established an expert panel in 2001 on the preparedness for widespread infectious diseases under its Health Science Advisory Council. The panel examined and made plans for diseases possibly associated with bioterrorism, especially six infectious diseases (including smallpox) classified by the CDC as category A. The panel published its report on MHLW preparedness for bioterrorism in March 2002 [49]. Thereafter, the MHLW panel on bioterrorism prepared a guideline for smallpox vaccination at the time of such bioterrorism. In May 2004, the MHLW published its detailed guidelines on counterterrorism that used smallpox (version 5) [50]. 
According to this guideline, if the exposure to smallpox virus is certain, regardless of the elapsed time thereafter, immediate vaccination is recommended. In ordinary times, however, vaccination is not indicated. Only when the likelihood of smallpox exposure increases should first responders, such as health service professionals, emergency and police officials, and port workers, be vaccinated. When smallpox cases are domestically found, a circle of people, as deemed necessary by the contact surveillance, should be vaccinated (called ring vaccination). Those who have never been vaccinated are to be prioritized for vaccination. Costs of the vaccination are to be covered by national and local governments.

\section{Adverse events of vaccination}

The adverse health effects after vaccine administration can be significant. Generally, about 250 out of every 1 million people vaccinated will probably have an adverse reaction, and an estimated 60 people out of approximately 100 million people vaccinated will likely have fatal reactions.

Complications can include postvaccinial encephalitis $(1 / 300,000$, one-fourth of these cases were fatal and several had permanent neurological residua); progressive vaccinia (vaccinia gangrenosa, where the vaccinial lesion progresses to involve adjacent and other parts of the skin, the bones, and the viscera, and are frequently fatal for those with immune deficiency disorders); eczema vaccinatum (vaccinial skin lesions extended to cover the areas of pre-existing or prior eczema); and generalized vaccinia, inadvertent inoculation, and different kinds of rashes (e.g., erythema multiforme) [51-53] (Table 2).

In the recent large-scale vaccination experience of the United States in 2002-2003, the anticipated and unanticipated local and systemic side effects were quantified $[54,55]$. Out of 730,580 Department of Defense personnel,

Table 2 Serious complications of smallpox (vaccinia) vaccination

1. Postvaccinal encephalitis
2. Progressive vaccinia (vaccinia gangrenosa, vaccinia necrosum)
3. Eczema vaccinatum, generalized vaccinia
4. Inadvertent inoculation (accidental implantation)
5. Vaccinia keratitis
6. Other rashes (e.g., erythema multiforme, Stevens-Johnson
syndrome, roseola vaccinia, toxic erythema, and postvaccinia
urticaria)
7. Fetal vaccinia
8. Myopericarditis
9. Acute ischemic events
10. Death

50 secondary contact transmissions, 2 tertiary, 62 autoinoculations (non-ocular), 16 autoinoculation (ocular), 35 suspect generalized vaccinia, 8 probable mild side effects, and 1 post-vaccination encephalitis were documented. On the other hand, of 40,422 health care workers and first responders, 20 autoimmune (non-ocular), 3 auto-inoculation (ocular), 2 suspect generalized vaccinia, 1 confirmed mild side effect, and 1 encephalitis were documented. There were 24 and 9 cases of ischemic events, 4 and 3 cases of dilated cardiomyopathy, and 86 and 21 cases of myopericarditis in each group, respectively. The milder post-vaccination signs and symptoms, such as itching, fatigue, and blisters, were more frequent $[56,57]$. Those mild physical symptoms were more frequently reported during visits with vaccinees not previously vaccinated. Whether coronary artery disease and/ or myopericarditis eventually resulted from the smallpox vaccinations is more controversial [58-60].

Rates of complications vary, depending upon the virus strains used for vaccination. In the 1960s, death occurred approximately once in every million primary vaccinations with fatalities resulting from progressive vaccinia, postvaccinial encephalitis, and eczema vaccinatum. Death in revaccinee populations occurred less commonly and almost entirely from progressive vaccinia [61]. Recent studies disclosed that vaccination with the NYCBH (New York City Board of Health) strain can lead to an average of 1.4 deaths per million vaccinations, and vaccination with the Lister vaccine can lead to an average of 8.4 deaths per million vaccinations $[62,63]$. The vaccine strain (Ikeda strain) previously used widely in Japan had a higher incidence of adverse reactions (10-38 deaths per million vaccinations) [64]. The LC16 strains ( $\mathrm{m} 0$ and $\mathrm{m} 8$ ), which were developed and clinically tested in Japan between 1971 and 1973, showed a lower incidence of vaccine side effects without severe adverse events, while having an efficacy equivalent to the other strains [65]. Recently, the CDC has begun distribution of a new generation of smallpox vaccinia (ACAM2000) to civilian laboratory personnel, the military, and state public health preparedness programs [66].

Vaccinia immune globulin (VIG) is recommended for the treatment of progressive vaccinia, severe generalized vaccinia, eczema vaccinia, and periocular autoinfection. It is also recommended as a prophylaxis if a patient with eczema or an immunosuppressed patient requires vaccinia vaccination [67, 68]. Smallpox vaccination just before conception or during pregnancy can result, in rare instances, in fetal vaccinia from a viral infection of the fetus (fetal vaccinia). There is no indication for the routine use of VIG for the prevention of fetal vaccinia. However, VIG should not be withheld if a pregnant woman experiences a condition in which VIG is needed [69]. Diagnostic and treatment guidelines for adverse events following exposure to vaccinia virus have been proposed $[70,71]$. 


\section{Deferral of smallpox vaccination}

In light of the possible adverse side effects, there are certain groups for whom elective vaccination is not recommended because of the greater risk of complications. CDC recommendations have been published, including nonemergency use of vaccine for laboratory workers occupationally exposed to the vaccinia virus and an interim updated bioterrorist response plan [72].

Five groups of persons are ordinarily considered at special risk for smallpox vaccine complications [37]: (1) persons with eczema or other significant exfoliative skin conditions; (2) persons with leukemia, lymphoma, or generalized malignancy who are receiving therapy with alkylating agents, anti-metabolites, radiation, or large doses of corticosteroids; (3) patients with HIV infection; (4) persons with hereditary immune deficiency disorders; and (5) pregnant women [73]. Cardiac deferral criteria include the following: a history of cardiac disease or three of the five major risk factors for atherosclerotic heart disease (hypertension, diabetes, hypercholesterolemia, smoking, or the history of heart disease in a first degree relative less than 50 years old [74]).

With exclusion of those individuals at risk for coronary artery disease, atopic dermatitis/eczema, and immunosuppression, it has been argued that smallpox vaccination can be administered with minimal risk [75]. Under epidemic circumstances, such contraindications will have to be weighed against the grave risks posed by smallpox. If available, VIG can be administered concomitantly with the vaccination to minimize the risk of complications in these persons [76].

In Japan, post-vaccination encephalitis was frequently reported after the 1940s. The victims and their families in the 1970s organized patient support groups and filed lawsuits against the national government claiming compensation. After the abolishment of the Smallpox Vaccination Act in 1976, vaccination has become a voluntary act. Only a quite limited number of people with special needs have received vaccinations. Those are currently managed under the guidelines for smallpox vaccination issued by the MHLW, which provide that inoculation against smallpox should not be given to those with the risk factors for its side effects. Smallpox vaccination is contraindicated for the following group of people in Japan [77] (Table 3).

\section{The preparedness program against smallpox terrorism attack in action}

A number of events have raised awareness about the potential threat of bioterrorism, including the suspected attempt to disseminate anthrax by Aum Shinrikyo in Japan
Table 3 Contraindications of smallpox vaccination in Japan

(1) Anaphylaxis with vaccines

(2) Presenting manifest pyrexia

(3) Serious acute diseases

(4) Immunologic disorders or receiving immunosuppresive treatments

(5) Pregnant

(6) Dermatologic diseases

Past and present skin eczema

Atopic dermatitis

Burns

Pustular rash

Chickenpox

Herpes zoster

(7) Other conditions

Past and present encephalitis

Cardiovascular diseases (such as coronary heart diseases, congestive heart failure, cardiomyopathies, exertional dyspnea)

More than three of the following conditions: hypertension, hypercholesteremia, hyperglycemia or diabetes mellitus, familial history of heart disease, and current smoking

[78], widespread occurrence of bioterrorist hoaxes, revelations about the bioweapons programs in the former Soviet Union and Iraq, and anthrax-related deaths, illnesses, and exposures in the US [79]. Beginning in mid-September 2001, the US experienced unprecedented biological attacks involving the intentional distribution of Bacillus anthracis through the postal system [80].

In response, the CDC in 2000 published its Biological and Chemical Terrorism: Strategic Plan for Preparedness and Response [81], which highlighted the vulnerability of the US to biological and chemical attacks, and listed implementation priorities and specific recommendations for terrorism preparedness. The CDC then prepared Public Health Infrastructure: A Status Report [82] for the Appropriations Committee of the US Senate, which emphasized the three areas of the public health infrastructure that were necessary to handle the threats of the twenty-first century, including bioterrorism: A skilled public health workforce, robust information and data systems, and effective health departments and laboratories. Vaccination of first responders as described above was the action plan set forth by the US Department of Homeland Security and FEMA [83]. The Smallpox Emergency Personnel Protection Act (2003) provides that a health care worker who is vaccinated pursuant to an emergency response plan and who has volunteered to become a covered individual is entitled to compensation without having to prove fault. Any person who contracts the vaccinia virus from a covered individual is also entitled to compensation under the no-fault program [84]. 
Although preparedness for a terrorist incident involving chemical, biological, radiological, nuclear, or high-yield explosive (CBRNE) devices or their agents follows the same principles used in emergency management for any catastrophic event, a community health care system will require more preparedness for these incidents than for natural or technological disasters [85]. Academic institutions have played increasingly important roles in these preparedness efforts [86]. Operational exercises have sometimes been conducted [87]. However, many hospitals still lack the capacity to respond to large-scale infectious disease outbreaks [88]. Similarly, in Japan, lagging preparedness of medical facilities against bioterrorism has been reported, although even its necessity has been argued [89].

\section{Conclusions}

In every successful effort against the spread of smallpox as a countermeasure against smallpox terrorism, medical professionals, especially public health professionals, infection control experts, and clinical practitioners, must play key roles. They are expected to find index cases, conduct epidemiological studies, and help people get vaccinated. They must, therefore, be well equipped with all necessary information (clinical pictures, disease spread, vaccination and its contra-indications, and treatment) as delineated in this article. This is especially so since almost all individuals today, including medical professionals, have never experienced actual smallpox cases personally.

Acknowledgments This study was supported by a Health Science Research Grant from the Japan Ministry of Health, Labor, and Welfare for the research project entitled "Study on the improvements of the health crisis management capacities among local governmental workers (2006-2008)" and a Scientific Grant-in-Aid from the Japan Society for the Promotion of Science for the project entitled "Strategic management and communications of health risks (2007-2009)."

\section{References}

1. Stein M, Hirshberg A. Medical consequences of terrorism. Surg Clin North Am. 1999;79:1537-52.

2. Mothershead JL. The new threat: weapons of mass effect. In: McGlown KJ, editor. Terrorism and disaster management: preparing healthcare leaders for the new reality. Chicago: Health Administration Press; 2004. p. 27-48.

3. Bureau of Public Affairs, United States Department of State. Patterns of global terrorism. Washington, DC: Department of State; 2009.

4. Tucker JB. Scourge: the once and future threat of smallpox. New York: Atlantic Monthly Press; 2001.

5. Stearn EW, Stearn AE. The effects of smallpox on the density of the Amerindian. Boston: Bruce Humphries; 1945.

6. Ciraulo DL, Frykberg ER, Feliciano DV, Knuth TE, Richart CM, Westmoreland CD, et al. A survey assessment of the level of preparedness for domestic terrorism and mass casualty incidents among eastern association for the surgery of trauma members. J Trauma. 2004;56:1033-41.

7. Braum BI, Wineman NV, Finn NL, Barbera JA, Schmaltz SP, Loeb JM. Integrating hospitals into community emergency preparedness planning. Ann Intern Med. 2006;144:799-811.

8. Fenner F, Wittek R, Dumbell KR. The Orthopox viruses. San Diego: Academic Press; 1989. p. 432.

9. Henderson DA, Inglesby TV, Bartlett JG, Ashcer MS, Eitzen E, Jarhrling PB, et al. Smallpox as a biological weapon. In: Henderson DA, Inglesby TV, O'Toole T, editors. Bioterrorism: guidelines for medical and public health management. Chicago: AMA Press; 2002. p. 99-120.

10. Fenner F, Henderson DA, Arita I, Jezek Z, Ladnyi ID. Smallpox and its eradication. Geneva: World Health Organization; 1988. p. 1460.

11. Chapin CV, Smith J. Permanency of the mild type of smallpox. J Prev Med. 1932;1:1-29.

12. Fenner F, Wittek R, Dumbell KR. The Orthopox viruses. San Diego: Academic Press; 1989. p. 434.

13. Mack TM. Smallpox in Europe, 1950-71. J Infect Dis. 1972; 125:161-9.

14. Mack TM, Thomas DB, Khan MM. Epidemiology of smallpox in West Pakistan, II: determinants of intravillage spread other than acquired immunity. Am J Epidemiol. 1972;95:157-68.

15. Dixon CW. Smallpox. London: J \& A Churchill Ltd.; 1962. p. 1460.

16. Wehrie PF, Posch J, Richter KH. An airborne outbreak of smallpox in a German hospital and its significance with respect to other recent outbreaks in Europe. Bull World Health Org. 1970;43:669-79.

17. Huggins JW, Bray M, Smee DF. Potential antiviral therapeutics for smallpox, monkeypox and other orthopoxvirus infections. Geneva: WHO Advisory Committee on Variola Virus Research; 2001.

18. Koplan J, Monsur KA, Foster SO. Treatment of variola major with adenine arabinoside. J Infect Dis. 1975;131:34-9.

19. Alibek K. Biohzard. New York: Random House Inc.; 1999.

20. Kim-Farley RJ, Celentano JT, Gunter C, Jones JW, Stone RA, Aller RD, et al. Standardized emergency management system and response to a smallpox emergency. Prehosp Disaster Med. 2003; 18(4):313-20.

21. Margolskee D. Improving vaccines, antimicrobials, and antitoxins through research. In: Levy BS, Sidel VW, editors. Terrorism and public health: a balanced approach to strengthening systems and protecting people. Oxford University Press, Oxford; 2003. pp. 286-304.

22. Hull HF, Danila R, Ehresmann K. Smallpox and bioterrorism: public health responses. J Lab Clin Med. 2003;142(4):221-8.

23. Nishiura $H$. Analysis of a previous smallpox vaccination study: estimation of the time period required to acquire vaccine-induced immunity as assessed by the revaccination. Southeast Asian J Trop Med Public Health. 2006;37(4):673-80.

24. Behbehani AM, Blower S. The smallpox story: life and death of an old disease. Microbiol Rev. 1983;47(4):455-509.

25. Hopkins DR. Princes and peasants. Chicago: University of Chicago Press; 1983.

26. Brachman PS. The public health response to the anthrax epidemic. In: Levy BS, Sidel VW, editors. Terrorism and public health: a balanced approach to strengthening systems and protecting people. Oxford University Press, Oxford; 2003. pp. 101-17.

27. Heymann DL. Smallpox containment updated: considerations for the 21st century. Int J Infect Dis. 2004;8(suppl. 2):S15-20.

28. World Health Organization. The global eradication of smallpox: final report of the Global Commission for the Certification of Smallpox Eradication. Geneva: WHO; 1980. 
29. Poland GA, Grabenstein JD, Neff JM. The US smallpox vaccination program: a review of a large modern era smallpox vaccination implementation program. Vaccine. 2005;23:2078-81.

30. Sternberg S. Scientists call for smallpox revaccination campaign. USA Today. 2002; December 23, p. 39.

31. Lindley M, Wortley PM, Winston C, Schwartz B. Programmatic factors related to smallpox vaccine update by healthcare workers and others. Infect Control Hosp Epidemiol. 2006;27:1242-5.

32. Altman LK. Panel rules out smallpox shots for all. New York Times. 2002; June 21, p. A16.

33. Centers for Disease Control and Prevention, Office of Communications. Smallpox vaccination program status by State. Atlanta: CDC; 2005.

34. Downie AW, McCarthy K. The antibody response in man following infection with viruses of the pox group, III: antibody response in smallpox. J Hyg. 1958;56:479-87.

35. El-Ad R, Roth Y, Winder A. The presence of neutralizing antibodies after revaccination against smallpox. J Infect Dis. 1990; 161:446-8.

36. McClain DJ. Smallpox. In: Sidell FR, Takafuji E, Franz DR, editors. Textbook of military medicine: medical aspects of chemical and biological warfare. Washington, DC: Borden Institute, Walter Reed Army Medical Center; 1997. pp. 539-59.

37. Blendon RJ, DesRoches CM, Benson JM, Herrmann MJ, TaylorClark K, Weldon KJ. The public and the smallpox vaccination: a national survey of emergency health care providers. N Engl $\mathrm{J}$ Med. 2003;348:426-32.

38. Wortley PM, Levy PS, Quick L, Shoemaker TR, Dahlke MA, Evans B, Burke B, Schwartz B. Predictors of smallpox vaccination among healthcare workers and other first responders. Am J Prev Med. 2007;32(6):538-41.

39. Ault A. US smallpox vaccine programme stalls as volunteers balk. Lancet. 2003;361:1626.

40. Wortley PM, Schwartz B, Levy PS, Quick LM, Evans B, Burke B. Healthcare workers who elected not to receive smallpox vaccination. Am J Prev Med. 2006;30(3):258-65.

41. Yih WK, Lieu TA, Rego VH, O'Brian MA, Shay MA, Yokoe DS. Attitudes of healthcare workers in US hospitals regarding smallpox vaccination. BMC Public Health. 2003;3:20-8.

42. Sato H, Tomio J, Tanaka Y, Iwasaki E. The public acceptance of smallpox vaccination to fight bioterrorism in Japan: results of a large-scale opinion survey in Japan. Environ Health Prev Med. 2010. doi:10.1007/s12199-010-0199-1.

43. Heiner GG, Fatima N, McCrumb FR. A study of intrafamilial transmission of smallpox. Am J Epidemiol. 1971;94:316-26.

44. Breman JG, Henderson DA. Diagnosis and management of smallpox. N Engl J Med. 2002;346:1300-8.

45. Dixon CW. Tripolitania, 1946: an epidemiological and clinical study of 500 cases, including trials of penicillin treatment. J Hyg. 1948;46:351-77.

46. Centers of Disease Control and Prevention. Interim smallpox response plans and guidelines. Atlanta: CDC; 2001.

47. Kretzchmar M, van den Hof S, Wallinga J, van Wijngaarden J. Ring vaccination and smallpox control. Emerg Infect Dis. 2004;10(5):832-41.

48. Centers for Disease Control and Prevention. Vaccinia (smallpox) vaccine, recommendations of the Advisory Committee on Immunization Practices (ACIP), 2001. Mortal Morb Wkly Rep. 2001;50:1-25.

49. Expert Panel on Pre-outbreak Management, Group for Infectious Diseases, Health Science Council, Ministry of Health, Labor and Welfare, Japan. Actions of Ministry of Health, labor and welfare against bioterrorism. Tokyo: MHLW; 2002.

50. Section for Tuberculosis and Infectious Diseases, Ministry of Health, labor and welfare, Japan. Tennento taio shishin (Smallpox management plan), 5th ed. Tokyo: MHLW; 2004.
51. Noji EK. Public health aspects of weapons of mass destruction. In: McGlown KJ, editor. Terrorism and disaster management: preparing healthcare leaders for the new reality. Chicago: Health Administration Press; 2004. p. 177-96.

52. Wittek R. Vaccinia immune globulin: current policies, preparedness, and product safety and efficacy. Int J Infect Dis. 2006;10:193-201.

53. Sidel VW, Levy BS. Biological weapons. In: Levy BS, Sidel VW, editors. Terrorism and public health: a balanced approach to strengthening systems and protecting people. Oxford University Press, Oxford; 2003. pp. 175-98.

54. Poland GA, Grabenstein JD, Neff JM. The US smallpox vaccination program: a review of a large modern era smallpox vaccination implementation program. Vaccine. 2005;23(17-18):2078-81.

55. Fillmore GL, Ward TP, Bower KS, Dudenhoefer EJ, Grabenstein JD, Berry GK, et al. Ocular complications in the Department of Defense smallpox vaccination program. Ophthalmology. 2004; 111:2086-93.

56. Klevens RM, Kupronis BA, Lawton R, Joseph D, Richards C. Monitoring health care workers after smallpox vaccination: findings from the hospital smallpox vaccination-monitoring system. Am J Infect Control. 2005;33:315-9.

57. Muralles AA, Ray P, Black S, Shinefield H, Casey C, Campbell $\mathrm{S}$, Chen R. Active telephone surveillance to evaluate adverse events among civilian smallpox vaccine recipients. Vaccine. 2006;24:476-84.

58. Eckart RE, Love SS, Atwood E, Arness MK, Cassimatis DC, Campbell CL, et al. Incidence and follow-up of inflammatory cardiac complications after smallpox vaccination. J Am Coll Cardiol. 2004;44:201-5.

59. Lewis FS, Norton SA, Bradshaw RD, Lapa J, Grabenstein JD. Analysis of cases reported as generalized vaccinia during the US military smallpox vaccination program, December 2002 to December 2004. J Am Acad Dermatol. 2006;55:23-31.

60. Ray CG. Poxviruses. In: Ryan KJ, Ray CG, editors. Sherris medical microbiology. 4th ed. New York: McGraw Hill; 2004. p. $525-8$.

61. Lane JM, Goldstein J. Adverse events occurring after smallpox vaccination. Sem Pediatr Infect Dis. 2003;14(3):189-95.

62. Kretzcshmar M, Wallinga J, Teunis P, Xing S, Mikolajczyk R. Frequency of adverse events after vaccination with different vaccinia strains. PloS Medicine. 2006;3(8):e272.

63. Auckland C, Cowlishaw A, Morgan D, Miller E. Reactions to smallpox vaccine in naive and previously vaccinated individuals. Vaccine. 2005;23:4185-7.

64. Hirayama M. Progress of research on attenuated smallpox vaccine in Japan. J Pediatr Infect Dis Immunol (Jpn Soc for Pediatr Infect Dis). 2008;20(1):65-71.

65. Hashizume S. Development of the attenuated smallpox vaccine, LC16m8, produced by cell culture. Modern Media. 2004;50(2): $28-33$.

66. Centers for Disease Control and Prevention. CDC interim guidance for revaccination of eligible persons who participated in the US Civilian Smallpox Preparedness and Response Program. Atlanta: CDC; 2008.

67. Henderson DA, Moss B. Smallpox and vaccinia. In: Plotkin SA, Orenstein WA, editors. Vaccines. Philadelphia: WB Saunders; 1999. p. 74-97.

68. Hopkins RJ, Lane MJ. Clinical efficacy of intramuscular vaccinia immune globulin: a literature review. Clin Infect Dis. 2004; 39:819-26.

69. Napolitano PG, Ryan MAK, Grabenstein JD. Pregnancy discovered after smallpox vaccination: is vaccinia immune globulin appropriate? Am J Obstet Gynecol. 2004;191:1863-7.

70. Nell P, Kohl KS, Graham PL, LaRussa PS, Marcy SM, Fulginiti VA, et al. Progressive vaccinia as an adverse event following 
exposure to vaccinia virus: case definition and guidelines of data collection, analysis, and presentation of immunization safety data. Vaccine. 2007;25:5735-44.

71. Thorne CD, Hirshon JM, Himes CD, McDiarmid MA. Emergency medicine tools to manage smallpox (vaccinia) vaccination complications: clinical practice guideline and policies and procedures. Ann Emerg Med. 2003;42(5):665-80.

72. Fauci A. Smallpox vaccination policy: the need for dialogue. N Engl J Med. 2002;346:1319-20.

73. Bicknell WJ. The case for voluntary smallpox vaccination. N Engl J Med. 2002;346:1323-5.

74. Casey CG, Iskander JK, Roper MH, Mast EE, Wen XJ, Torok TJ. Adverse events associated with smallpox vaccination in the United States, January-October 2003. JAMA. 2005;294:273443.

75. Malone JD. Pre-event smallpox vaccination for healthcare workers revisited - the need for a carefully screened multidisciplinary cadre. Int J Infect Dis. 2006;11:93-7.

76. Parkman PD, Hardegree MC. Regulation and testing of vaccines. In: Plotkin SA, Orenstein WA, editors. vaccines. Philadelphia: WB Saunders; 1999. p. 1131-43.

77. Section for Tuberculosis and Infectious Diseases, Ministry of Health, Labor and Welfare, Japan. Guidelines on smallpox vaccination. Tokyo: MHLW, 2004.

78. Senate Government Affairs Permanent Subcommittee on Investigations. Global Proliferation of Weapons of Mass Destruction: a case study on the Aum Shinrikyo, October 31, 1995. Washington, DC: FAS, 2001.

79. Barbera J, Macintyre A, Goston L, Inglesby TV, O’Toole $\mathrm{T}$, DeAtley $\mathrm{C}$, et al. Large-scale quarantine following biological terrorism in the United States. In: Henderson DA, Inglesby TV, O'Toole T, editors. Bioterrorism: guidelines for medical and public health management. Chicago: AMA Press; 2002. p. 221-32.

80. Gerberding JL, Hughes JM, Koplan JP. Bioterrorism preparedness and response: clinicians and public health agencies as essential partners. In: Henderson DA, Inglesby TV, O'Toole T, editors. Bioterrorism: guidelines for medical and public health management. Chicago: AMA Press; 2001. p. 29-32.

81. Centers for Disease Control and Prevention. Biological and chemical terrorism: strategic plan for preparedness and response. Mortal Morb Wkly Rep. 2000; 47 (RR-15).

82. Centers for Disease Control and Prevention. Public Health's Infrastructure: a status report. Prepared for the Appropriations Committee of the United States Senate, 2000. Atlanta: CDC, 2001.

83. Centers for Disease Control and Prevention. Protecting Americans: smallpox vaccination program. Atlanta: CDC, 2002.

84. Wayland WR, Brant MH. Legal and ethical considerations in disaster situations. In: McGlown KJ, editor. Terrorism and disaster management: preparing healthcare leaders for the new reality. Chicago: Health Administration Press; 2004. p. 231-53.

85. Mothershead JL. Disaster planning for terrorism. In: McGlown KJ, editor. Terrorism and disaster management: preparing healthcare leaders for the new reality. Chicago: Health Administration Press; 2004. p. 51-80.

86. Atchison CG, Uden-Holman T, Greene BR, Prybil LD. Developing the academic institution's role in response to bioterrorism: the Iowa Center for Public Health Preparedness. J Public Health Manage Pract. 2003;9(5):418-26.

87. Balch D, Taylor C, Rosenthal D, Bausch C, Warner D, Morris R. Shadow Bowl 2003: A collaborative exercise in community readiness, agency cooperation, and medical response. Telemed $\mathbf{J}$ e-Health. 2004;10(3):330-42.

88. Heinrich J. Infectious disease outbreaks: Bioterrorism preparedness efforts have improved public health response capacity, but gaps remain Testimony before the Committee on Government Reform, House of Representatives. Washington, DC: Government Accountability Office; 2003.

89. Endo Y. Preparedness of medical facilities in the event of largescale infectious disease epidemics. Koshu Eisei. 2007;71(6): $523-8$. 